\title{
MATERIAL VOLKANIK SEBAGAI PENYUSUN UTAMA TANAH MERAH DI ATAS BATUAN KARBONAT KARANGSARI WONOSARI
}

\author{
VOLCANIC MATERIALS AS A MAIN CONSTITUENT OF RED SOILS \\ OVERLYING THE CARBONATE ROCK OF KARANGSARI, WONOSARI
}

\author{
Djoko Mulyanto \\ Prodi Ilmu Tanah, Universitas Pembangunan Nasional Veteran Yogyakarta \\ Corresponding author E - mail: j.mulyanto@upnyk.ac.id
}

\begin{abstract}
The phenomenon of soil coloring that develops in carbonate rocks, which are generally white in color, is very interesting to study the minerals. The purpose of this study was to examine the mineral composition of the soil. Analysis of mineral properties includes: mineral fraction of fine sand (powder) and clay fraction of soil, as well as limestone that underlie the soil. Mineral identification using XRD. The results showed that the $7{ }^{\circ} \mathrm{A}$ haloysite mineral dominated the clay fraction, in addition to iron oxides, especially goethite. The fine sand fraction showed feldspar, biotite, cristobalite and quartz minerals in the first layer while the lower layer consists of goethite, maghemite-magnetite, quartz, and rhodocrosite. Analysis of limestone minerals (powder) showed that calcite is a very dominant mineral, the others are quartz and maghemite-magnetite. Based on the mineral composition of both sand and clay fractions, and also ratio of $\mathrm{Fe}$-soil/ $\mathrm{Fe}$-limestone it is suggested that the soil parent material much be influenced by volcanic materials.
\end{abstract}

Keywords: Goethite, haloysite $7^{\circ}$ A, red soil, volcanic materials

\begin{abstract}
ABSTRAK
Gejala kewarnaan tanah yang berkembang pada batuan karbonat yang secara umum berwarna putih sangat menarik untuk dikaji mineralnya. Tujuan penelitian ini adalah menelaah komposisi mineral tanah. Analisis sifat mineral meliput: mineral fraksi pasir halus (bubuk) dan fraksi lempung tanah, serta batugamping yang membawahi tanah tersebut. Identifikasi mineral mengunnakan XRD. Hasil penelitian menunjukkan bahwa mineral haloisit $7^{\circ} \mathrm{A}$ sangat mendominasi fraksi lempung tanah, disamping oksida-oksida besi khususnya gutit. Fraksi pasir halus menunjukkan mineral feldspar, biotit, kristobalit dan kuarsa pada lapisan pertama sedangkan lapisan bawah terdiri atas gutit, maghemit-magnetit, kuarsa, dan rhodokrosit. Analisis mineral batugamping (powder) menunjukkan mineral kalsit sangat dominan, sedangkan mineral yang lain adalah kuarsa dan maghemit-magnetit. Berdasarkan komposisi mineral baik fraksi pasir maupun lempung, serta nisbah $\mathrm{Fe}$ tanah/ batuan, diduga bahwa bahan induk tanah banyak dipengaruhi oleh material volkanik.
\end{abstract}

Kata Kunci: Tanah merah, material volkanik, haloisit $7^{\circ}$ A, gutit 


\section{PENDAHULUAN}

Warna tanah merupakan salah satu parameter yang sangat penting untuk menginterpretasi sifat-sifat tanah (Mulyanto et al., 2006). Oksida-oksida dan hidroksida besi dan mangan merupakan pigmen warna tanah yang sangat kuat (Schwermant dan Fanning, 1976). Ditambahkan oleh Notohadiprawiro (2000) bahwa warna tanah selain dipengaruhi oleh kedua persenyawaan tersebut juga dipengaruhi oleh humus serta komposisi mineralnya. Komposisi mineral dalam tanah akan berubah sejalan dengan proses pedogenesis yang dialami tanah serta dapat mempengaruhi warna tanah yang terbentuk. Dalam pembentukan tanah terjadi proses alih rupa (transformation) bahan/ mineral primer menjadi mineral sekunder dan zat-zat terlarut, serta alih tempat (translocation) bahan-bahan hasil pelapukan yang didistribusikan ke lain tempat dalam tubuh tanah untuk membentuk horizon-horizon. Proses alih rupa dan alih tempat sangat dipengaruhi oleh kondisi lingkungan dan pewatakan bahan induknya.

Mineral ortoklas, albit dan mikrolin merupakan mineral primer yang sering terdapat pada batugamping dan dolomit dari segala umur (Pettijohn, 1975). Berdasarkan hal di atas kiranya perlu juga dipertimbangkan asal dari mineral-mineral lempung pada tanah merah yang boleh jadi merupakan hasil pelapukan mineral-mineral tersebut. Proses pelapukan kimia pada batugamping khususnya melalui pelarutan, bersifat menyeluruh (congruent dissolution). Sedangkan pada mineral aluminosilikat bersifat tidak menyeluruh (incongruent dissolution) (Birkeland, 1984). Gamping akan larut dan menghasilkan ion kalsium dan bikarbonat yang keduanya larut dalam air, dan peka terhadap pelindian. Mineral aluminosilikat menghasilkan kation-kation larut air dan mineral lempung yang tidak larut. Reaksi tersebut dapat dilukiskan sebagai berikut :

$$
\begin{aligned}
& \text { (i). } \mathrm{CaCO}_{3}+\mathrm{CO}_{2}+\mathrm{H}_{2} \mathrm{O} \quad<===>\mathrm{Ca}^{2+}+2 \mathrm{HCO}_{3}^{-} \\
& \text {(ii). Aluminosilikat }+\mathrm{H}_{2} \mathrm{O}+\mathrm{H}_{2} \mathrm{CO}_{3}<====>\text { mineral lempung + kation-kation }+\mathrm{OH}^{-} \\
& +\mathrm{HCO}_{3}{ }^{-}+\mathrm{H}_{4} \mathrm{SiO}_{4}
\end{aligned}
$$

Dari reaksi tersebut terlihat bahwa, tanah yang terbentuk dari bahan gampingan sangat dipengaruhi oleh jenis dan jumlah pengotornya. Bila batugamping sebagai bahan induk tanah, tentunya dibutuhkan bahan dengan volume yang sangat besar. MacLeod (1980) menghitung kebutuhan $40 \mathrm{~cm}$ tanah yakni diperlukan $130 \mathrm{~m}$ batugamping, selanjutnya diduga bahwa residu yang terlepas dari batugamping selama denudasi harus terakumulasi dengan laju $8 \times 10^{-6} \mathrm{~cm}$ selama $5 \times 10^{6}$ tahun, sehingga bila dihitung menjadi tidak logis. Penelitian yang dilakukan oleh Foster dan Chittleborough (2003) menunjukkan bahwa Terra Rossa berasal dari lebih dari satu bahan induk yang dipengaruhi oleh translokasi material dari lereng atasnya (up slope) setelah mengalami proses geomorfik, sedangkan sifat kimia profil tanahnya banyak terpengaruh oleh dolomit. Sebelumnya Yaalon dan Ganor's (1975) telah menghitung kecepatan denudasi batugamping untuk 1-2 cm di Judea dan Galilee Israel yang memerlukan waktu selama 1000 tahun. Hal tersebut tentunya sangat dipengaruhi oleh jumlah air sebagai pelaku proses utama pelarutan dan tentunya sangat berbeda dengan lingkungan karst beriklim tropis khususnya di Indonesia (Gunungkidul). Fenomena tersebut tentunya juga sangat berbeda dengan bahan yang berasal dari mineral silikat karena sumbangan unsur Si dan Al sebagai kerangka tanah sangat melimpah. 


\section{BAHAN DAN METODE PENELITIAN}

Analisis mineral fraksi lempung menggunakan XRD (Rigaku Ultima IV X-ray Diffractometer) dengan sistem orientasi 6 perlakuan : jenuh $\mathrm{Mg}$; $\mathrm{Mg}+$ gliserol ; jenuh $\mathrm{K}$ $20{ }^{\circ} \mathrm{C}$; K-100 ${ }^{\circ} \mathrm{C} ; \mathrm{K}-350{ }^{\circ} \mathrm{C}$ dan $\mathrm{K}-550{ }^{\circ} \mathrm{C}$. Mineral fraksi pasir halus dan batugamping secara bubuk (powder) dengan XRD. Interpretasi macam mineral berdasarkan Brindley et al. (1980). Analisis kimia meliputi oksida besi bebas amorfus dan kristalin menggunakan metode pelarutan selektif. Oksida besi bebas yang bersifat amorfus menggunakan ekstrak asam oksalat (0,2 $\mathrm{M}$ ammonium oksalat $\mathrm{pH}$ 3- Metode Tamm, 1922 cit. Blakemore et al., 1987), sedangkan oksida besi bebas yang bersifat kristalin menggunakan ekstrak ditionit sitrat bikarbonat yakni Na-dithionit sitrat $\mathrm{pH}$ 7,3 (Mehra dan Jackson, 1960 cit. Blakemore et. al., 1987). Ekstrak dithionit lebih kuat dari ekstrak oksalat, sehingga perhitungan oksida besi kristalin berdasarkan pengurangan hasil ekstrak dithionit-hasil ekstrak oksalat. Besi total dengan ekstrak asam-asam kuat (Blakemore et. al., 1987). Nilai $\mathrm{pH} \mathrm{H}_{2} \mathrm{O}$ menggunakan Metode Potensiometrik. Analisis geokimia batuan dengan ekstrak asam-asam kuat, unsur diidentifikasi dengan AAS.

\section{HASIL DAN PEMBAHASAN}

\section{Analisis sifat kimia tanah dan batuan}

Hasil analisis kimia untuk parameter tertentu yakni $\mathrm{pH} \mathrm{H}_{2} \mathrm{O}$ menunjukkan status yang agak masam yakni sekitas 6 walaupun di lingkungan batuan karbonat. Hal tesebut menunjukkan perkembangan tanah yang cukup lanjut yang diikuti pelindian kalsium yang cukup intensif. Kondisi lingkungan nampaknya cukup mendorong proses tersebut, yakni topografi yang berombak dan sifat batuan yang mempunyai porositas sekunder yang ditunjukkan oleh fenomena retakan-retakan batugamping yang tersingkap di permukaan tanah.

Analisis sifat-sifat kimia yang meliputi Fe total, Fe kristalin dan nisbah Fe kristalin/ Fe total tanah terdapat pada Tabel 1.

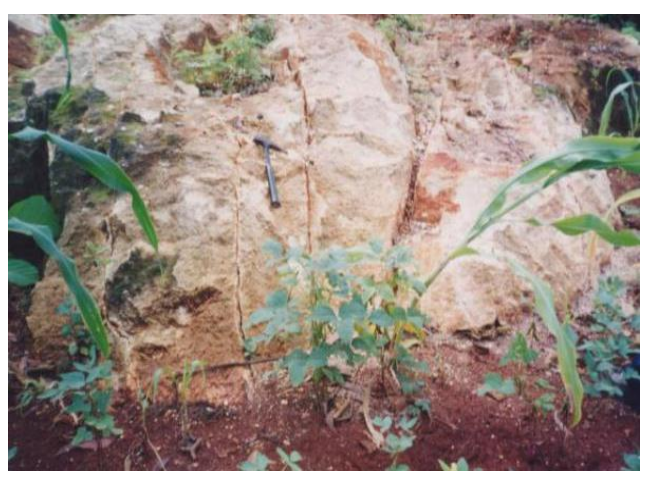

Gambar 1. Singkapan batugamping di lingkungan tanah merah yang menunjukakan pola retakan-retakan.

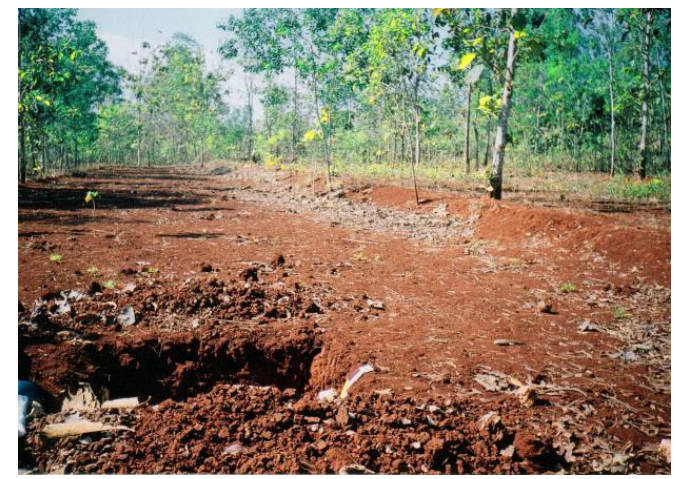

Gambar 2. Lingkungan tanah merah di Karangsari. 
D. Mulyanto: Material Volkanik sebagai Penyusun Utama Tanah Merah

Tabel 1. Nisbah Fe total tanah/ Fe batugamping dan Fe kristalin/ Fe total tanah

\begin{tabular}{ccccccc}
\hline Lapisan & $\begin{array}{c}\text { Nilai } \\
\mathbf{p H} \\
\left(\mathbf{H}_{2} \mathbf{O}\right)\end{array}$ & $\begin{array}{c}\text { Fe total } \\
\text { Tanah } \\
(\text { Fe-t) }\end{array}$ & $\begin{array}{c}\text { Fe kristalin } \\
(\mathbf{F e}-\mathbf{})\end{array}$ & $\begin{array}{c}\text { Fe } \\
\text { Batugam } \\
\mathbf{p i n g}\end{array}$ & $\begin{array}{c}\text { Nisbah } \\
\text { Fe tanah/ } \\
\text { Fe batugam } \\
\text { pingn }\end{array}$ & $\begin{array}{c}\text { NisbahFe } \\
\text { kristalin/ } \\
\text { Fe total }\end{array}$ \\
\hline & & & $(\%)$ & & & \\
\hline I & 5,87 & 8.67 & 2.20 & 0.14 & 62 & 0.25 \\
II & 5,91 & 9.38 & 2.04 & 0.14 & 67 & 0.21 \\
III & 5,94 & 10.84 & 2.17 & 0.14 & 77,4 & 0.20 \\
IV & 6,04 & 8.00 & 2.05 & 0.14 & 57 & 0.26 \\
V & 6,05 & 9.77 & 2.15 & 0.14 & 70 & 0.22 \\
VI & 6,05 & 7.33 & 2.24 & 0.14 & 52 & 0.31 \\
VII & 6,58 & 7.83 & 2.16 & 0.14 & 56 & 0.28 \\
\hline
\end{tabular}

Nisbah Fe kristalin/ Fe total tanah berkisar 0,21 - 0,31. Durr et al., (2001) menggunakan nilai rata-rata nisbah Fe-k / Fe-t sebagai indeks pelapukan tanah yang berasal dari mineral silikat dengan angka 0,7. Hasil penelitiannya menunjukkan bahwa indek pelapukan > 0,7 yang mengatakan bahwa tingkat pelapukan tanah tersebut sangat tinggi. Berdasarkan pendapat tersebut dengan ini dapat disimpulkan bahwa tanah merah di Karangsari belum mengalami tingkat pelapukan yang lanjuti karena hanya berkisar $0,21-0,31$.

Nisbah Fe total tanah terhadap Fe batugamping yang membawahinya sangat tinggi, yakni berkisar dari 52 - 77,4. Hal tersebut menunjukkan bahwa bila kita meyakini bahwa tanah berasal dari pelapukan batugamping maka akan dibutuhkan massa batuan yang sangat besar. Rata-rata kandungan Fe batuan beku yang dalam bentuk $\mathrm{Fe}_{2} \mathrm{O}_{3}$ dan $\mathrm{FeO}$ secara berturut-turut 0,2 dan 3,8 (Clarke dan Washington, 1924 cit. Mohr et. al., 1972) yang setara dengan Fe secara total $=3,14 \%$, sehingga bisa dianalogikan bahwa bila tanah merah tersebut berasal dari batuan beku, maka nisbah Fe tanah total / Fe batuan beku sekitar 2,44 - 3,61 yakni jauh lebih rendah dibanding nisbah Fe total tanah/ Fe batugamping yakni 52 - 77,4. Berdasarkan perbandingan tersebut nampaknya bahwa tanah merah Karangrejek bukan berasal dari batugamping secara keseluruhan melainkan sangat dipengaruhi secara signifikan oleh material volkanik.

Tabel 2. Hasil analisis geokimia batugamping.

\begin{tabular}{|c|c|c|c|c|c|c|c|c|c|c|}
\hline \multirow{3}{*}{ KET. } & $\mathrm{SiO}_{2}$ & $\mathbf{A l}_{2} \mathbf{O}_{3}$ & $\mathrm{Fe}_{2} \mathrm{O}_{3}$ & MnO & $\mathrm{CaO}$ & MgO & $\mathrm{Na}_{2} \mathrm{O}$ & $\mathrm{TiO}_{2}$ & $\mathbf{P}_{2} \mathbf{O}_{5}$ & LOI \\
\hline & \multicolumn{10}{|c|}{ Persen $(\%)$} \\
\hline & \multicolumn{6}{|c|}{ Batugamping berlapis (Bedded limestone) } & di daerah & Karangsa & & \\
\hline $\begin{array}{l}\text { Bahan } \\
\text { induk }\end{array}$ & 0,54 & 0,33 & 0,20 & 0,021 & 55 & 0,20 & 0,011 & $\mathrm{tt}$ & 0,240 & 43,30 \\
\hline
\end{tabular}

Berdasarkan Tabel 2. di atas menunjukkan bahwa kandungan Si dan Al pada batugamping sangat rendah bila dibandingkan dengan kandungannya di batuan beku yang sangat melimpah. Sebagai perbandingan kandungan $\mathrm{SiO}_{2}$ dan $\mathrm{Al}_{2} \mathrm{O}_{3}$ secara berturut-turut pada batuan beku (Mohr et al., 1972) dibandingkan batugamping adalah 191 dan 46 kali atau 10,9\% dan 4,6\%. Perbandingan tersebut sangat nyata sehingga bila menyakini bahwa tanah berasal dari batugamping biasanya bersolum dangkal. 
Tanah merah di lingkungan kawasan karst khususnya di bagian dolin biasanya relatif dalam karena berasal dari proses agradasi oleh hasil erosi tanah dari tempat yang lebih tinggi.

\section{Analisis XRD batugamping dan fraksi pasir halus}

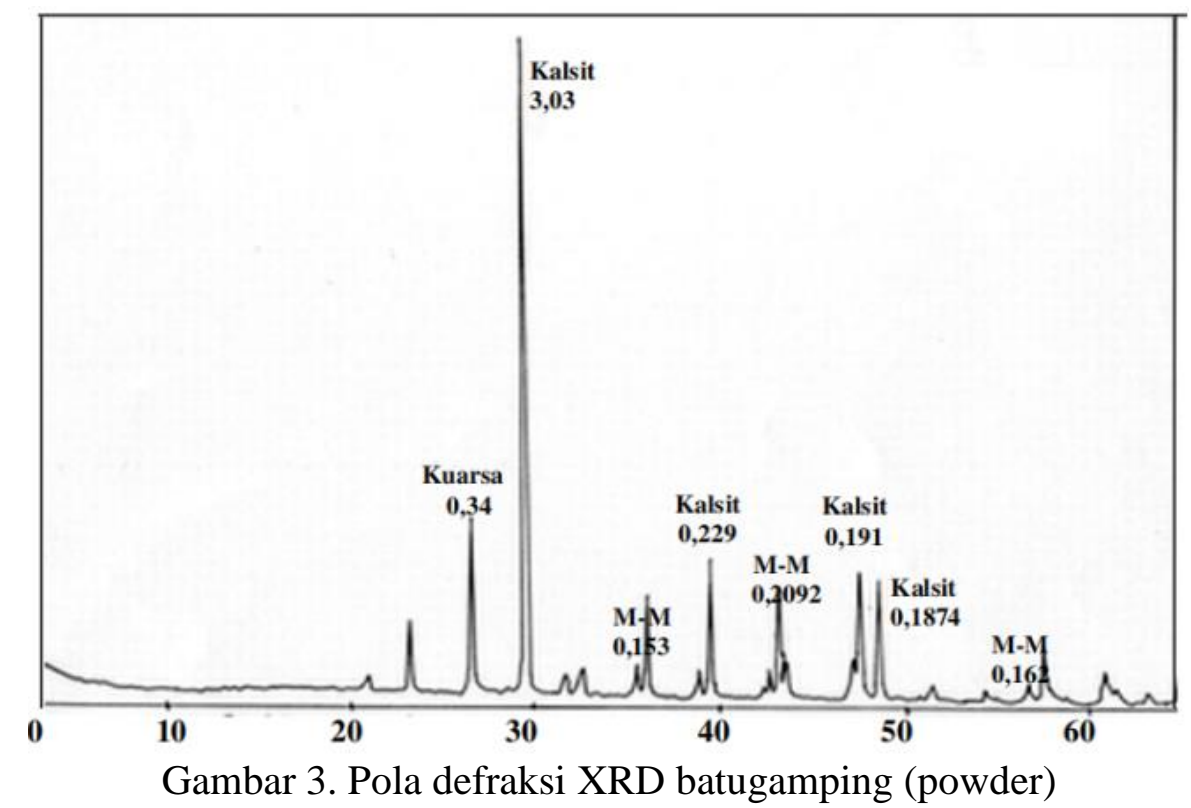

Mineral yang menyusun batugamping didominasi oleh kalsit, oksida besi maghemit-magnetit dan kuarsa. Tidak munculnya mineral silikat kecuali kuarsa sangat bolehjadi karena sampelnya berupa bubuk batuan yang sangat didominasi oleh kalsit. Kemungkinan yang lain memang kandungan mineral silikatnya sangat sedikit dibanding kandungan kalsitnya yang sangat melimpah. Apabila hanya mendasarkan kandungan mineral yang terdapat pada batugamping tersebut berdasar pola XRD yang terlihat, maka dapat disimpulkan secara langsung bahwa tanah yang terbentuk hanya dikomposisi oleh mineral volkanik dari material non karbonat. Oleh karena itu perlu dicermati hasil analisis mineral primer dari fraksi pasirnya.

Tidak ditemukannya mineral primer kecuali kuarsa di lapisan 7 (dekat batugamping) nampaknya sejalan dengan hasil analisis bubuk batugamping. Kemungkinan yang lain adalah bahwa semua mineral primer khususnya mineral silikat kecuali kuarsa sudah menjadi lempung seperti yang disampaikan Pettijohn (1975). Hasil dari pelapukan tersebut antara lain membentuk oksida-oksida besi maghemit-magnetit dan gutit, sedangkan rodokrosit $\left(\mathrm{MnCO}_{3}\right)$ dapat berasal dari $\mathrm{Ca}$ hasil pelarutan kalsit dan Mn yang diduga berasal kegiatan organisme penyusun batugamping. Menurut Menezes (2015 cit. Atmoko et al., 2016) rodhokrosit merupakan isomorf mineral karbonat. Sehingga ketika ada pengkayaan senyawa $\mathrm{MnO}$ dalam batugamping, maka sebagian unsur $\mathrm{Ca}^{+2}$ yang berpasangan dengan anion komplek $\left(\mathrm{CO}_{3}^{-2}\right)$ dapat digantikan oleh unsur $\mathrm{Mn}^{+2}$ dan membentuk mineral rodhokrosit $\left(\mathrm{MnCO}_{3}\right)$. 


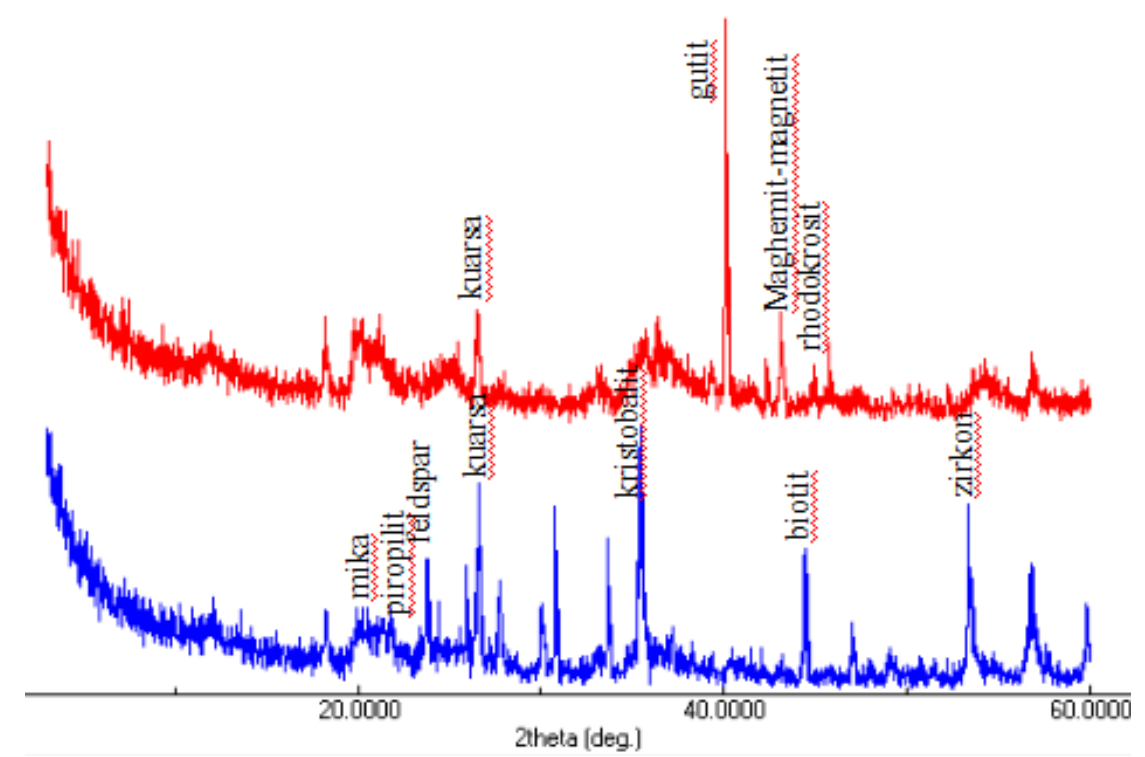

Gambar 4. Pola defraksi XRD fraksi pasir halus lapisan 1 (bawah) dan 7 (atas dekat bahan induk)

Fraksi pasir di lapisan atas dijumpai adanya beberapa mineral silikat seperti feldspar, mika, biotit yang bisa menjadi lempung. Chursman dan Lowe (2012) mengatakan bahwa fedspar bisa terhidrolisis menghasilkan lempung kaolinit. Munculnya mineral cristobalit pada lapisan atas menunjukkan sumbernya dari volkanik Kuarter (Mizota et. al., 1987). Biotit bisa berubah menjadi muskovit kemudian illit, dan biotit juga bisa menjadi klorit (Peters and Hofmann, 1984).

\section{Analisis XRD fraksi lempung tanah}

Analisis mineral lempung dengan XRD menunjukkan mineral tipe 1:1 yang ditandai dengan hilangnya puncak defraksi setelah pemanasan $550{ }^{\circ} \mathrm{C}$. Gambar 5 . menunjukkan pola defraksi dengan puncak-puncak $7,3{ }^{\circ} \mathrm{A}$ dan $3,55{ }^{\circ} \mathrm{A}$, dengan perlakuan baik dengan penjenuhan $\mathrm{Mg}, \mathrm{Mg}+$ gliserol maupun penjenuhan dengan $\mathrm{K}$ dan pemanasan dari $20{ }^{\circ} \mathrm{C}-350^{\circ} \mathrm{C}$ menunjukkan puncak defraksi yang relatif tetap. Perlakuan penjenuhan $\mathrm{K}$ dengan pemanasan $550{ }^{\circ} \mathrm{C}$ memperlihatkan lenyapnya puncak-puncak defraksi tersebut. Berdasarkan hal tersebut, menurut Brindley et al., (1980) diinterpretasi sebagai haloisit $7{ }^{\circ} \mathrm{A}$. Hillier dan Ryan (2002) juga telah mengidentifikasi puncak-puncak defraksi $7,2^{\circ} \mathrm{A}$ dan $3,58^{\circ} \mathrm{A}$ sebagai haloisit $7{ }^{\circ} \mathrm{A}$. Lenyapnya puncak-puncak defraksi dengan perlakuan $\mathrm{K}-550{ }^{\circ} \mathrm{C}$ menunjukkan bahwa tanah merah tidak mengandung jenis lempung tipe 2:1. Puncak-puncak defraksi 4,$17 ; 2,67 ; 2,18$ dan $1,69^{\circ} \mathrm{A}$ diidentifikasi sebagai oksida-oksida besi gutit.

Gambar 6 tersebut menunjukkan pola defraksi dengan puncak-puncak 7,29 ${ }^{\circ} \mathrm{A}$ dan 3,56 ${ }^{\circ} \mathrm{A}$, perlakuan baik dengan penjenuhan $\mathrm{Mg}, \mathrm{Mg}+$ gliserol maupun penjenuhan dengan $\mathrm{K}$ dan pemanasan dari $20^{\circ} \mathrm{C}-350{ }^{\circ} \mathrm{C}$ menunjukkan puncak defraksi yang relatif tetap. Perlakuan penjenuhan $\mathrm{K}$ dengan pemanasan $550{ }^{\circ} \mathrm{C}$ juga memperlihatkan lenyapnya puncak-puncak defraksi tersebut. Berdasarkan hal tersebut, menurut Brindley et al., (1980) diinterpretasi sebagai haloisit $7{ }^{\circ} \mathrm{A}$, bukan sebagai kaolinit yang mempunyai puncak defraksi $7,16^{\circ} \mathrm{A}$. Lenyapnya puncakpuncak defraksi dengan perlakuan K-550 ${ }^{\circ} \mathrm{C}$ menunjukkan bahwa tanah merah tidak 


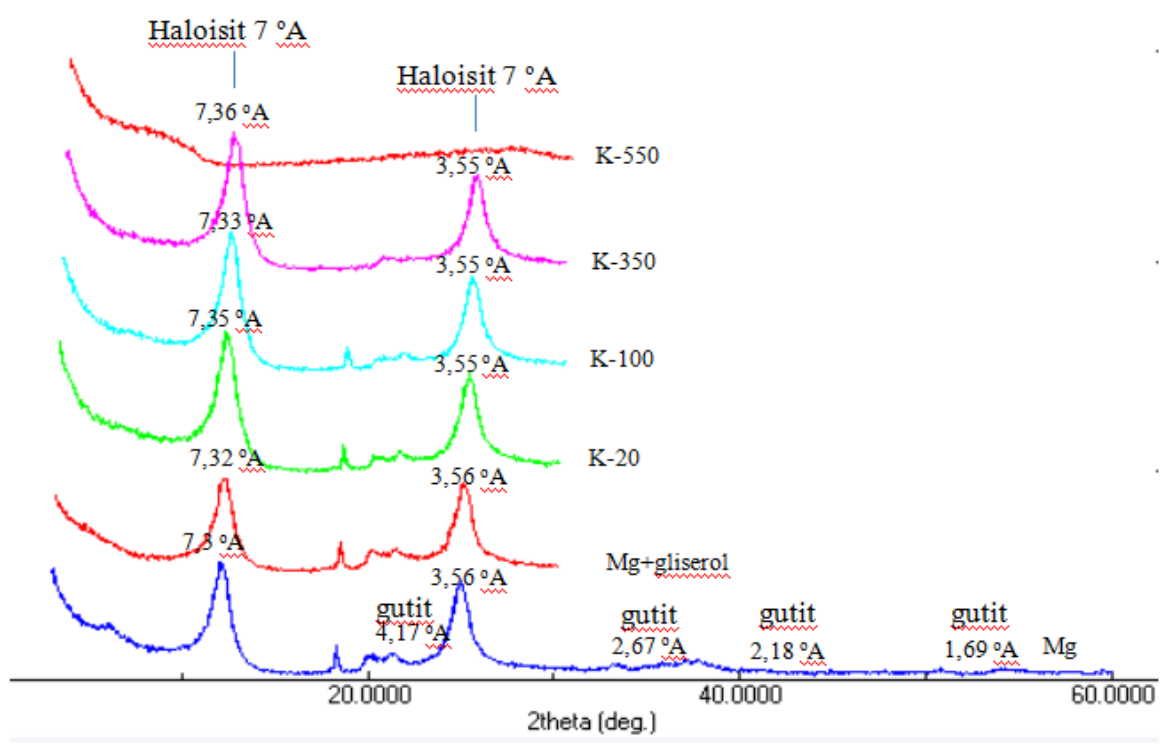

Gambar 5. Pola XRD lapisan tanah atas

mengandung jenis lempung tipe $2: 1$. Puncak-puncak defraksi 4,17;2,67;2,18 dan $1,69^{\circ} \mathrm{A}$ diidentifikasi sebagai oksida-oksida besi gutit. Hasil di atas menunjukkan bahwa komposisi mineral lempung lapisan 1 dan 7 relatif sama, yakni didominasi haloisit $7{ }^{\circ} \mathrm{A}$ dan oksida-oksida besi khususnya gutit. Durn et al., (2001) mengatakan bahwa oksida-oksida besi yang mendominasi tanah-tanah merah di Istria Kroasia adalah gutit dan hematit. Tidak munculnya hematit di tanah merah Karangrsari tersebut diduga karena tingkat kelembaban tanah lebih tinggi sehingga oksida-oksida besi tersebut tidak teroksidasi secara kuat. Komposisi jenis mineral lempung tanah merah ini berbeda dengan tanah merah di daerah Mediteran yang ditemukan Durn (2003) yang terdiri atas illit, vermikulit dan chlorit. Sebetulnya bila mencermati analisis fraksi pasir yang menunjukkan adanya biotit berarti juga berpotensi membentuk khlorit sebagaimana yang dikatakan oleh Peters dan Hofmann (1984).

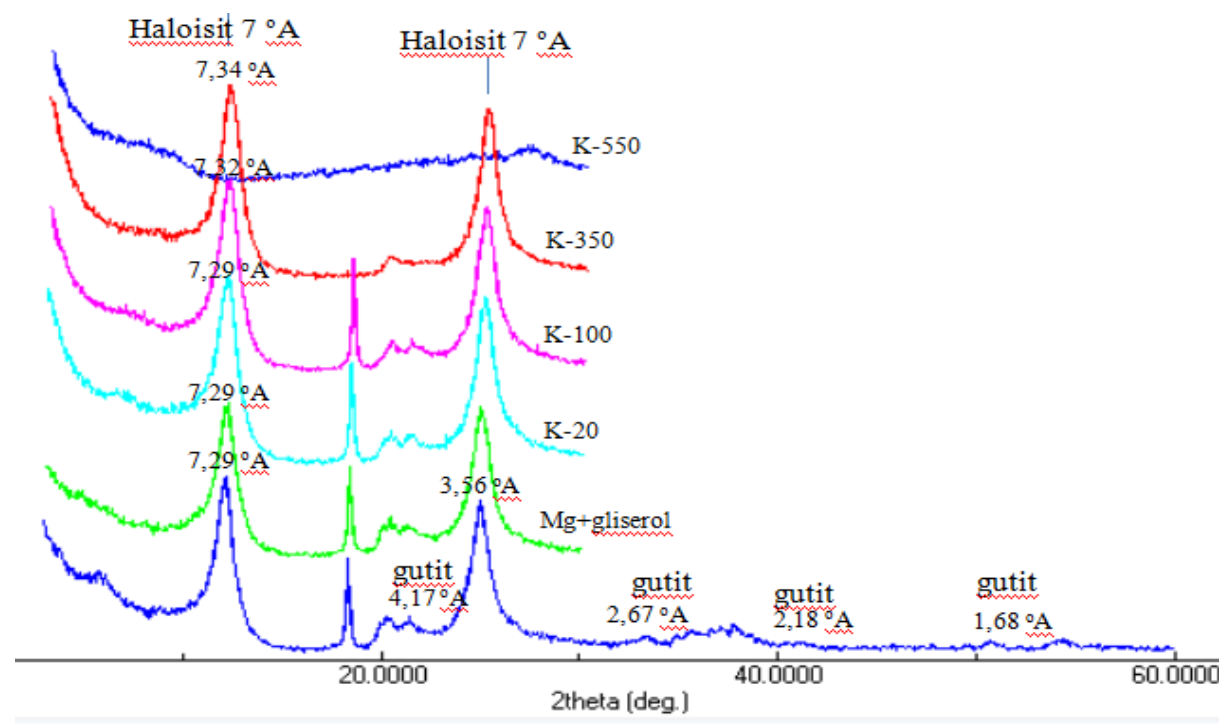

Gambar 6. Pola XRD lempung lapisan atas dengan analisis orientasi 
Gambar 7 menunjukkan pola defraksi XRD lempung lapisan 1 dan 7 pada perlakuan penjenuhan $\mathrm{Mg}$, yang secara jelas tidak menunjukkan pola yang berbeda. Belum terbentuknya kaolinit sangat bolehjadi karena tingkat pelapukan tanah yang belum lanjut yang sejalan dengan nilai indek pelapukan <0,7 yakni berkisar 0,21 0,31 .

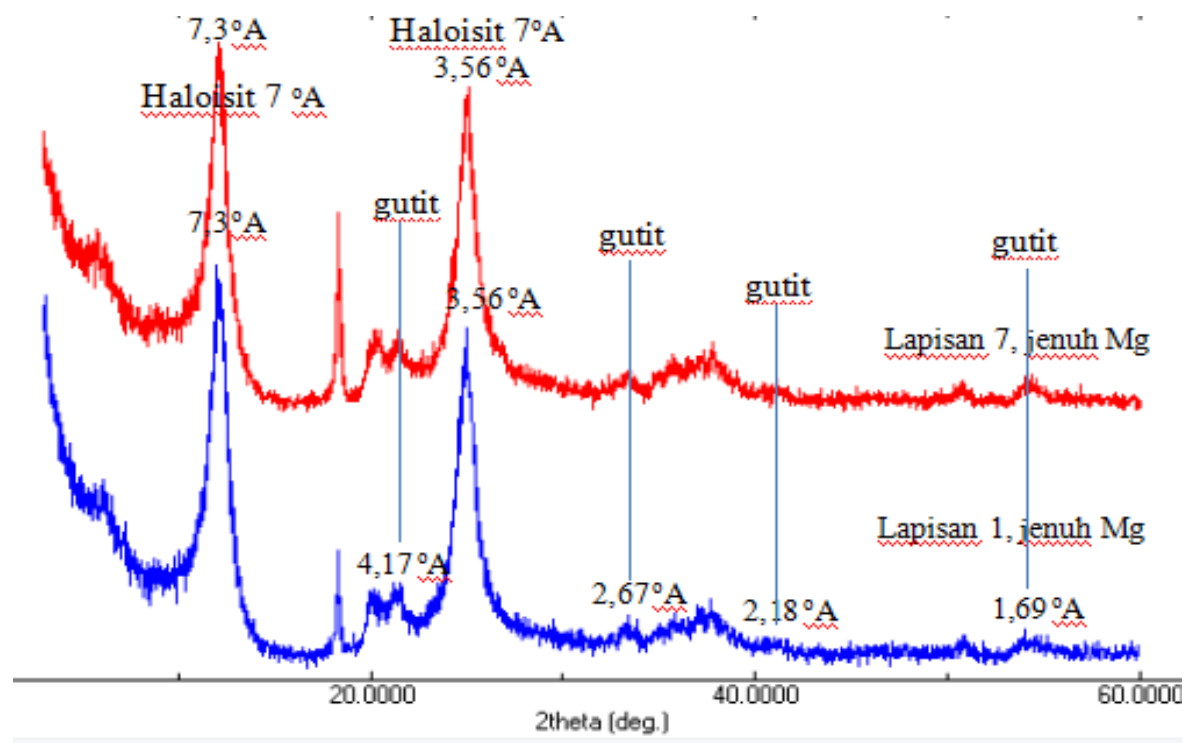

Gambar 7. Pola defraksi fraksi lempung lapisan 1 (bawah) dan 7, dengan perlakuan penjenuhan $\mathrm{Mg}$

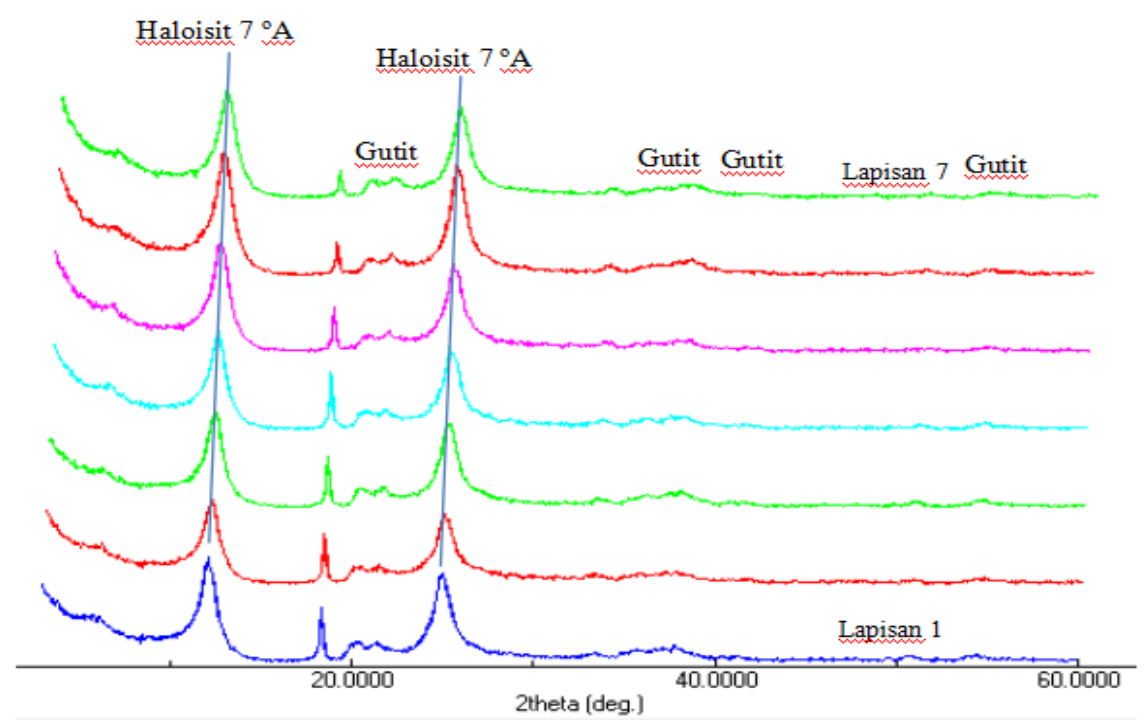

Gambar 8. Pola XRD fraksi lempung lapisan 1 - 7 dengan penjenuhan $\mathrm{Mg}$

Secara umum pola XRD lempung tanah merah lapisan $1-7$ menunjukkan pola yang relatif sama. Hal ini menunjukkan bahwa jenis dan komposisi fraksi lempung relatif sama (Gambar 8). Penulis menginterpretasikan bahwa Haloisit $7{ }^{\circ} \mathrm{A}$ adalah metahaloisit yang mirip dengan kaolinit bila kehilangan molekul airnya. Birkeland 
(1984) mengatakan bahwa proses pencucian yang relatif tinggi menyebabkan kationkation basa rendah dan $\mathrm{pH}<7$, hal ini mendukung terbentuknya kaolinit dan haloisit. Bentuk haloisit terutama dari material volkanik dengan fungsi waktu akan terbentuk kaolinit. Kondisi lingkungan tersebut nampaknya sejalan dengan penjelasan sebelumnya, yakni bentuk lahan yang berombak - bergelombang, dan konsentrasi oksida besi terutama gutit yang cukup dominan dapat berdampak membaiknya perembihan air pada kolom tanah. Sifat batugamping yang membawahi tanah-tanah merah sebagian besar menunjukkan adanya retakan-retakan (Gambar 1.), sehingga kondisi lingkungan tersebut sangat mendukung terjadinya pelindihan katin-kation basa yang cukup intensif. Hal tersebut sejalan dengan nilai $\mathrm{pH}$ tanah \pm 6 walaupun di lingkungan batugamping yang kaya kalsium.

\section{Genesis lempung}

Kyne et al., (2013) mengatakan bahwa haloisit dan kaolinit secara kimia mempunyai rumus yang sama namun dibedakan oleh strukturnya. Haloisit berbentuk memanjang seperti tabung sedangkan kaolinit berlembar. Hasil penelitian menunjukkan bahwa penyusun fraksi lempung adalah haloisit $7{ }^{\circ} \mathrm{A}$. Penulis berkeyakinan bahwa mineral lempung haloisit $7{ }^{\circ} \mathrm{A}$ yang dimaksud adalah metahaloisit yang sangat mirip dengan kaolinit. Mineral ini diduga hasil sintesis dari pelapukan mineral-mineral primer khususnya felspar sebagaimana teranalisis dalam fraksi pasir halus.

Pembentukan kaolinit di tanah merah dari mineral silikat khususnya dapat dilukiskan sebagai berikut :

$$
\begin{array}{ccc}
2 \mathrm{KAlSi}_{3} \mathrm{O}_{8}+2 \mathrm{H}^{+}+9 \mathrm{H}_{2} \mathrm{O} \\
\text { (orthoklas) }
\end{array} \quad \rightarrow \quad \begin{gathered}
\mathrm{H}_{4} \mathrm{Al}_{2} \mathrm{Si}_{2} \mathrm{O}_{9}+4 \mathrm{H}_{4} \mathrm{SiO}_{4}+2 \mathrm{~K}^{+} \\
\text {(kaolinit) }
\end{gathered}
$$

(Bohn et al.,, 1979; Birkeland, 1983)

$$
\begin{array}{ccc}
2 \mathrm{NaAlSi}_{3} \mathrm{O}_{8}+2 \mathrm{H}^{+}+9 \mathrm{H}_{2} \mathrm{O} \\
\text { (albite) }
\end{array} \quad \rightarrow \quad \begin{gathered}
\mathrm{H}_{4} \mathrm{Al}_{2} \mathrm{Si}_{2} \mathrm{O}_{9}+4 \mathrm{H}_{4} \mathrm{SiO}_{4}+2 \mathrm{Na}^{+} \\
\text {(kaolinit) }
\end{gathered}
$$

(Birkeland, 1983).

Merino dan Banerjee (2008) berpendapat tentang pembentukan kaolinit tanah merah (Terra Rossa) di lingkungan batugamping dengan mekanisme sebagai berikut:

$$
2,7 \mathrm{Calc}+2 \mathrm{Al}^{+3}+2 \mathrm{Si}(\mathrm{OH})_{4}+\mathrm{H}_{2} \mathrm{O} \rightarrow \text { kaolinit }+2,7 \mathrm{Ca}^{+2}+2,7 \mathrm{HCO}_{3}{ }^{-}+3,3 \mathrm{H}^{+}
$$

$$
2,7 \mathrm{CaCO}_{3}+2 \mathrm{Al}^{+3}+2 \mathrm{SiO}_{2}+5 \mathrm{H}_{2} \mathrm{O} \rightarrow \mathrm{Al}_{2} \mathrm{Si}_{2} \mathrm{O}_{5}(\mathrm{OH})_{4}(\mathrm{kaol})+2,7 \mathrm{Ca}^{++}+2,7 \mathrm{HCO}_{3}+3,3 \mathrm{H}^{+}
$$

Reaksi tersebut didahului oleh Al dan Si larut air (hasil pelapukan mineral silikat) non gamping yang menuju kalsit untuk membentuk lempung kaolinit. Kaolinit ditemukan sebagai fase mineral lempung pedogenik utama dalam Terra Rossa dari Istria, Croatia (Durn, 2003).

Munculnya kristobalit yang signifikan pada fraksi pasir halus menunjukkan adanya bahan volkanik kuarter di wilayah tersebut yang diduga mempunyai andil yang sangat besar sebagai bahan induk tanah. Sebelumnya (Mulyanto et. al.,, 2000; Sudihardjo, 2002a; 2002b) melaporkan adanya material amorf seperti alofan pada 
fraksi lempung dan mineral-mineral volkanik yang sangat melimpah di atas karst wilayah Bedoyo-Gunungsewu. Berdasarkan hal tersebut diduga bahwa haloisit pada tanah merah merupakan hasil rekombinasi Si dan Al dari pelapukan feldspar. Disamping itu ada kemungkinan bahwa haloisit juga berasal dari pelapukan bahan tak larut dari batugamping setelah bahan karbonatnya hilang.

\section{KESIMPULAN}

Lempung tanah merah di atas batuan karbonat Wonosari adalah haloisit $7^{\circ} \mathrm{A}$ dan oksida-oksida besi khususnya gutit yang sangat melimpah. Oksida besi gutit menyebabkan tanah berwarna merah. Bahan induk tanah merah tersebut diduga hasil pelapukan mineral volkanik khususnya feldspar yang berumur Kuarter. Bahan tak larut khususnya mineral silikat dari batugamping diduga juga ikut menyumbang sebagai bahan induk tanah merah Karangsari-Wonosari.

\section{DAFTAR PUSTAKA}

Atmoko, D.D., A. D. Titisari., A. Idrus. 2016. Mineralogy and Geochemistry of Ponjong Red Limestone, Gunungkidul, Daerah Istimewa Yogyakarta - Indonesia. Ris.Geo.Tam Vol. 26, No.1 (55-69). DOI: 10.14203/risetgeotam2016.v26.269.

Birkeland, P. W. 1984. Soil and Geomorphology. Oxford University Press, New York, Oxford. $372 \mathrm{p}$.

Brindley, G.W. and Brown, Gr. 1980. Crystal Structure of Clay Minerals and X-ray Identification. Mineralogical Society, London.

Bohn, H.L., Brian L. McNeal, and George O’Connor. 1979. Soil Chemistry. A Wiley Interscience Publication. John Wiley \& Sons, New York, Chichester, Brisbane, Toronto, $392 \mathrm{p}$.

Churchman, G.J.; Lowe, D.J. 2012. Alteration, Formation, and Occurrence of Minerals in Soils. In: Huang, P.M.; Li, Y; Sumner, M.E (editor) "Handbook of Soil Sciences. $2^{\text {nd }}$ edition. Vol. I: Properties and Processes". CRC Press (Taylor \& Francis), Boca Raton, FL,pp.20.1-20.72.

Durn, G., D. Slovenec and M. Ovia. 2001. Distribution of Iron and Manganese in Terra Rossa from Istria and its Genetic Implications. Geologia Croatica 54/1:27-36

Durn, G. 2003. The Terra Rossa in the Mediterranean Region: Parent Materials, Composition and Origin. hrcak.srce.hr/file/6257. [27-10-2011].

Foster, J. and D. Chittleborough. 2003. Soil Development on Dolomites of the Cambrian Normanville Group Delamere, South Australia. In: Roach I.C. Advances in Regolith pp. 131-132. CRC LEME.

Hillier, S. And P.C. Ryan. 2002. Identification of halloysite (7 AÊ) by ethylene glycol solvation: the 'MacEwan ffect'. ClayMinerals (2002)37, 487-496

Kyne, R., P. Holling, N. H. Jansen, and D.R. Cooke. 2013. Supergene and Hypogene Halloysite in a Porphyry-Epithermal Environment at Cerro la Mina, Chiapas, Mexico. Economic Geology August 2013v. 108 no. 5 p. 1147-1161

Macleod D.A. 1980. The origin of the Red Mediterranean soils in Epirus, Greece. Journal of Soil Science 31, 125-136.

Merino, E. and A. Banerjee. 2008. Terra Rossa Genesis, Implications for Karst, and 
Eolian Dust: A Geodynamic Thread. The Journal of Geology Vol 116: 62-75.

Mizota, C.; N. Toh and Y. Matsuhisa. 1987. Origin of cristobalite in soils derived from volcanic ash in temperate and tropical regions. Geoderma. Vol. 39: 323-330.

Mohr, E.C.J., F.A. Van Baren, J. and Van Schuylenborgh. 1972. Tropical Soils. A Comprehensive of Their Genesis. Mouton, Ichtiar Baru, Van Hoeve. The Hague, Paris, Djakarta.

Mulyanto, D., D. Shiddieq, dan Indrayana. 2000. Mengaji Asal Bahan Andik pada Pedon Gunung Gatel Wilayah Karst Bukitseribu Gunung Kidul. Prosiding Konggres Nasional HITI VII, Bandung 2 - 4 November 1999.

Mulyanto, D.,T. Notohadikusumo, B.H. Sunarminto. 2006. Hubungan Tingkat Pemerahan Tanah di Atas Batuan Karbonat dengan Komponen-Komponen Pembentuknya. Jurnal Habitat Vol. 17 No.3: 235-245.

Notohadiprawiro, T. 2000. Tanah dan Lingkungan. Pusat Studi Sumber Daya Lahan UGM, 187 hal.

Peters, TJ. And B. Hofmann. 1984. Hydrothermal Clay Mineral Formation in BiotiteGranite in Northern. Clay Minerals (19): 579-590.

Pettijohn, F.J. 1975. Sedimentary Rocks. Second Edition. Harper \& Brothers, New York, $628 \mathrm{p}$.

Schwertmann, U., and D.S. Fanning. 1976. Iron - Manganese Concretions in Hydrosequences of Soils in Bavaria. Soil Sci.Soc.Am.J. 40:731-738.

Sudihardjo, A.M. 2002a. Transformasi Mineral Amorf Alofan ke Mineral Kristalin Secara Mikroskopik pada Tanah-Tanah Andisol di Kawasan Karst Gunungkidul Yogyakarta. J. Tanah dan Air. 3 (1): 1-9.

2002b. Phenomena and Environment of Karst Area on Andisolization of Soils in Gunung Kidul, Yogyakarta Special Province. J. Tanah dan Air. 3 (2): 57-68.

Yaalon, D.H. and Ganor, E. (1975). Rates of aeolian dust accretion in the Mediterranean and desert fringe environments of Israel. Int. Sediment. Congress, Nice, 2, 169174. 